\title{
Refletindo sobre ações de informação no laboratório de tecnologias intelectuais - LTi
}

Isa Maria Freire

\begin{abstract}
Doutora em Ciência da Informação pela Universidade Federal da Paraíba. Docente permanente no Programa de Pós-Graduação em Ciência da Informação da Universidade Federal da Paraíba, Brasil. Coordeadora da Rede de projetos do Laboratório de Tecnologias Intelectuais - Lti
\end{abstract}

http://dx.doi.org/10.1590/1981-5344/2684

Apresenta uma reflexão sobre as ações de informação no regime de informação do Laboratório de Tecnologias Intelectuais - LTi do Departamento de Ciência da Informação da Universidade Federal da Paraíba. Compartilha os resultados preliminares de pesquisa com o objetivo de acompanhar e discutir sobre as ações de pesquisa - ensino - extensão informação em desenvolvimento no LTi e analisa as atividades a partir do modelo das ações de informação proposto por González de Gómez. Resume o quadro teórico-metodológico que abrange a abordagem do regime de informação, o escopo e procedimentos da pesquisa, e descreve a rede de projetos do LTi na perspectiva dos estratos e modalidades das ações de informação, bem como dos seus respectivos atores sociais. Analisa as ações de informação em curso no regime de informação do $L T i$, ressaltando a articulação entre os domínios e estratos das ações em desenvolvimento.

Palavras-chave: Rede conceitual; Regime de informação; Ações de informação; Políticas de informação; Laboratório de Tecnologias Intelectuais - LTi.

\section{Reflecting on the information actions in the intellectuals technologies laboratory- LT}

Reflects on the actions of information in the information system of the Project Intellectuals Technologies 
Laboratory - LTi Department of Information Science at the Federal University of Paraíba. Shares the preliminary results of research aiming to monitor and discuss the actions of research - teaching - extension information and analyzes $\mathrm{LTi}$ development activities from the model information actions proposed by González Gómez. Summarizes the theoretical and methodological framework that covers the approach of information regime, the scope and procedures of the research, and describes a network of LTi projects in view of the strata, and modalities of action information, as well as their respective social actors. Analyzes the current information provision in LTi information system, highlighting the link between domains and strata of actions in development.

Keywords: Conceptual network; System of information; Information actions; Policy information; Intellectuals Technologies Laboratory - LTi.

Recebido em 11.01.2016 Aceito em 26.09.2016

\section{Introdução}

Neste trabalho, refletimos sobre a experiência de tecer uma rede conceitual no tear da Ciência da Informação, reunindo os fios conceituais representados pelos construtos responsabilidade social e tecnologias intelectuais, no contexto do regime de informação do Projeto Laboratório de Tecnologias Intelectuais (LTi), em desenvolvimento no Departamento de Ciência da Informação da Universidade Federal da Paraíba (UFPB). Particularmente, o presente trabalho resulta de reflexão sobre o regime de informação em desenvolvimento no LTi. ${ }^{1}$

O LTi iniciou suas atividades em 2009, com apoio do Conselho Nacional de Desenvolvimento Científico e Tecnológico (CNPq), através do edital Ciências Humanas CNPq - Capes 2010, dos editais Universal (2009, 2011 e 2014), do Programa Institucional de Bolsas de Iniciação Científica (PIBIC Graduação e Ensino Médio) e do Programa de Bolsas de Protuvidade do $\mathrm{CNPq}$, bem como do Programa de Bolsas de Extensão (MEC/Probex) da UFPB. O Projeto LTi tem como propósito contribuir para a formação acadêmica nos cursos de graduação e pós-graduação da UFPB, a partir da experiência de integração de atividades de pesquisa - ensino extensão, bem como atender a demandas de informação da sociedade em geral.

Certamente o modelo de rede conceitual aqui descrito, e a partir do qual refletimos, poderá ser aplicado a outras situações onde sejam necessárias políticas e ações para o desenvolvimento de competências em

\footnotetext{
${ }^{1}$ Pesquisa com apoio do CNPq - Modalidade PQ.
} 
informação, mediante uso e apropriação de tecnologias intelectuais por sujeitos dos diversos grupos de possíveis usuários, na sociedade.

Dessa forma, esperamos contribuir para a discussão sobre o valor das aplicações teóricas desse campo científico para as questões de informação na sociedade contemporânea, tais como a necessária democratização do acesso a fontes de informação na web, as competências informacionais relevantes nesse processo e a responsabilidade social dos profissionais da informação.

\section{0 tear conceitual}

Como urdidura para os fios do nosso texto, apresentamos, a seguir, modelo de rede conceitual a partir da qual desenvolvemos nossa reflexão sobre as ações de pesquisa - ensino - extensão no espaço do LTi, na perspectiva da Ciência da Informação.

\subsection{A trama da rede}

Em 1993, Wersig sugeriu para a ciência da informação uma estrutura teórica que considerasse menos a formulação de leis gerais e mais a de estratégias de ação, mediante uma abordagem de entrelaçamento de conceitos científicos. Neste modelo teórico, os conceitos fundamentais "se constituem semelhantemente a ímãs, ou 'atratores', atraindo os materiais [teóricos ou empíricos] para fora [dos seus respectivos campos científicos] e reestruturando-os dentro da estrutura científica da informação" (WERSIG, 1993, p. 231).

Dessa forma, seria possível tecer uma rede conceitual na Ciência da Informação, a partir da qual fios conceituais do próprio campo e de outros campos científicos poderiam se entretecer, "fazendo a rede ainda mais inclusiva e mais apertada, de modo a aumentar seu caráter científico" (WERSIG, 1993, p. 232). Nesse sentido, o autor propõe que "Desde que todas as coisas estão conectadas entre si [...] a Ciência da Informação deveria desenvolver algum tipo de sistema conceitual de navegação" (WERSIG, 1993, p. 239), um 'padrão que une' esses fios conceituais, constituindo a urdidura do texto no tear onde tecemos a rede conceitual que fundamenta o LTi.

Este modelo de abordagem teórica na Ciência da Informação foi aplicado por Freire (2001), a partir de proposição de Wersig e Neveling (1975), para demonstrar a responsabilidade social da Ciência da Informação na sociedade contemporânea. Este construto também se constitui no atrator conceitual das ações de informação desenvolvidas no LTi, a partir do qual será desenvolvido um contexto em cuja trama se destacam - dentre outros também relevantes -, os construtos de 'tecnologias intelectuais' e 'regime de informação'.

Seguindo o modelo de Lévy (1994, p. 42) consideramos tecnologias intelectuais 
[...] tanto as formas de expressão simbólica (que, p.ex., evoluíram das narrativas míticas às equações quânticas) quanto as tecnologias de informação em si mesmas (p.ex., a escrita em tabuinhas de barro, as iluminuras medievais, a imprensa e os computadores). Podemos chamá-las, também, de 'tecnologias soft' em contraponto às tecnologias de produção material (que evoluíram, p.ex., desde o machado de pedra até os satélites de comunicação).

Ainda de acordo com Lévy (1994, p. 42, grifos nossos), essas tecnologias intelectuais

[...] situam-se fora dos sujeitos cognitivos, como este computador sobre minha mesa ou este [texto] em suas mãos. Mas elas também estão entre os sujeitos como códigos compartilhados, textos que circulam, programas que copiamos, imagens que imprimimos e transmitimos por via hertziana. [...] As tecnologias intelectuais estão ainda nos sujeitos, através da imaginação e da aprendizagem.

No modelo teórico em aplicação no LTi, o construto de 'responsabilidade social da Ciência da Informação' tem um papel central entre os demais conceitos da rede, os quais assumem funções teórica ou interpretativa, como no caso dos construtos 'rede conceitual', 'regime de informação' e 'inteligência coletiva'; ou metodológica, como no caso do construto 'pesquisa-ação'; ou operacional, como no caso dos construtos 'tecnologias intelectuais' e 'cultura informacional' ou 'forma de vida'. $\mathrm{Na}$ Figura 1, a seguir, descrevemos a rede conceitual do Projeto LTi:

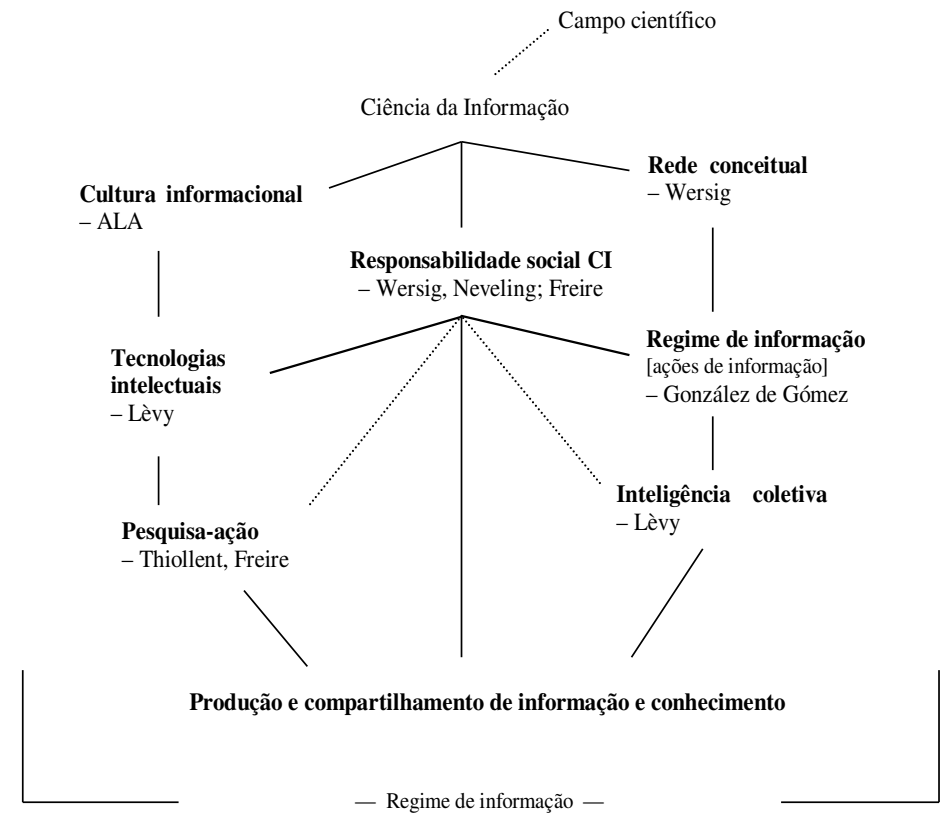

Figura 1 - Rede conceitual do Projeto LTi

Fonte: FREIRE (2012). 
Os construtos que constituem a urdidura da trama da rede conceitual que estamos tecendo no tear da Ciência da Informação são: tecnologias intelectuais, subsidiando as ações de informação no seu estrato mimeomórfico; competências em informação, subsidiando as ações de informação no seu estrato polimórfico; e responsabilidade social, subsidiando as ações de informação no seu estrato regulatório. Neste desenho da abordagem também identificamos construtos do contexto utilizados para descrever a ambiência da sociedade em rede, tendo como corolário a proposição de uma 'inteligência coletiva', definida por Lèvy (2000, p. 78) como "uma inteligência distribuída em toda a parte" e fundamentada nas qualidades humanas.

Nesse sentido, ressaltamos as oportunidades de comunicação proporcionadas pela sociedade em rede, corroborando Lèvy (2000) quando propõe a formulação de projetos que promovam a produção compartilhada de informação e conhecimento pelos diversos grupos que constituem a sociedade contemporânea, mediante apropriação e uso de tecnologias intelectuais virtuais. No Projeto LTi entrelaçamos este fio conceitual com a proposição de uma responsabilidade social da Ciência da Informação, identificando a possibilidade de emergência de uma inteligência coletiva nos espaços sociais de produção e trocas de informação, na sociedade em rede.

Ademais, como não poderia deixar de ser, a trama da nossa rede conceitual é tecida no tear histórico da contemporaneidade, que se realiza no mundo da vida das sociedades humanas e no mundo virtual das comunidades constituídas no ciberespaço ${ }^{2}$, mediante a Internet.

\subsection{A ambiência do regime de informação}

O desenvolvimento das tecnologias digitais de comunicação possibilitou a produção de novos suportes e ofereceu à informação a possibilidade de adotar diferentes formatos, consolidando o processo de 'explosão informacional' iniciado nos anos 1950. Nesse sentido, como assinalam Unger e Freire (2008, p. 84),

Ao tornar a informação a principal matéria-prima para o aumento da produtividade, em nível mundial, a sociedade contemporânea tornou também necessária a organização e gestão desse insumo. [...] Sendo assim, de um regime industrial formado pelas tecnologias de comando e comunicação, passamos para um regime de produção que se qualifica como sociedade da informação e comunica através de tecnologias cada vez mais digitais.

Na interpretação de Unger e Freire (2008), trata-se de um sistema social que resulta de inovações nas tecnologias de informação e

\footnotetext{
2 Para Lévy (1999, p. 36, grifos do autor), "o ciberespaço [também chamado de rede] é o novo meio de comunicação que surge da interconexão mundial dos computadores. O termo especifica não apenas a infraestrutura material da comunicação digital, mas também o universo oceânico de informações que ela abriga, assim como os seres humanos que navegam e alimentam esse universo".
} 
comunicação, as quais, em conjunto com a relevância da informação, provocaram profundas alterações nos diversos setores da sociedade, embora sua importância e influência seja desigualmente distribuída nos diferentes estratos sociais e regiões geográficas.

Nessa nova ordem econômica mundial, que se anuncia nas explanações científicas e na economia das tecnologias digitais, é que ocorre a 'nova relevância de um fenômeno antigo' (WERSIG; NEVELING, 1975 citados por Freire, 2001) e o regime de informação, com seus sistemas de informação e linguagens documentárias, inicia sua hegemonia sobre o regime industrial, na sociedade contemporânea. (UNGER; FREIRE, 2008, p. 85, grifos nossos) $)^{3}$

Para Frohmann (1995, s.p.), o regime de informação pode ser definido como "qualquer sistema estável ou rede nos quais os fluxos informacionais transitam por determinados canais [de específicos produtores, via estruturas organizacionais específicas] para consumidores ou usuários específicos". Nessa perspectiva, redes de rádio e televisão, distribuidoras de filmes, publicações acadêmicas, bibliotecas, se constituem em nós de redes de informação ou elementos de regimes de informação específicos. González de Gómez, por sua vez, trabalha o conceito de regime de informação na concepção de dispositivo ${ }^{4}$, definindoo como

Um modo de produção informacional dominante numa formação social, conforme o qual serão definidos sujeitos, instituições, regras e autoridades informacionais, os meios e os recursos preferenciais de informação, os padrões de excelência e os arranjos organizacionais de seu processamento seletivo, seus dispositivos de preservação e distribuição. (GONZÁLEZ DE GÓMEZ, 2002, p. 34).

No seu estudo sobre o regime de informação, Delaia (2008) resumiu a descrição dos elementos do regime de informação, conforme González de Gómez, como Figura

\footnotetext{
${ }^{3}$ Conforme WERSIG, G., NEVELING, U. The phenomena of interest to information science. The Information Scientist, v. 9, n. 4, p. 187-219, 1975.

${ }^{4}$ Etimologicamente, o termo latino dispositio seria a tradução do termo grego diathesis; é definido na filosofia moderna como aquilo que facilita, faz algo possível ou limita as possibilidades de algo.
} 


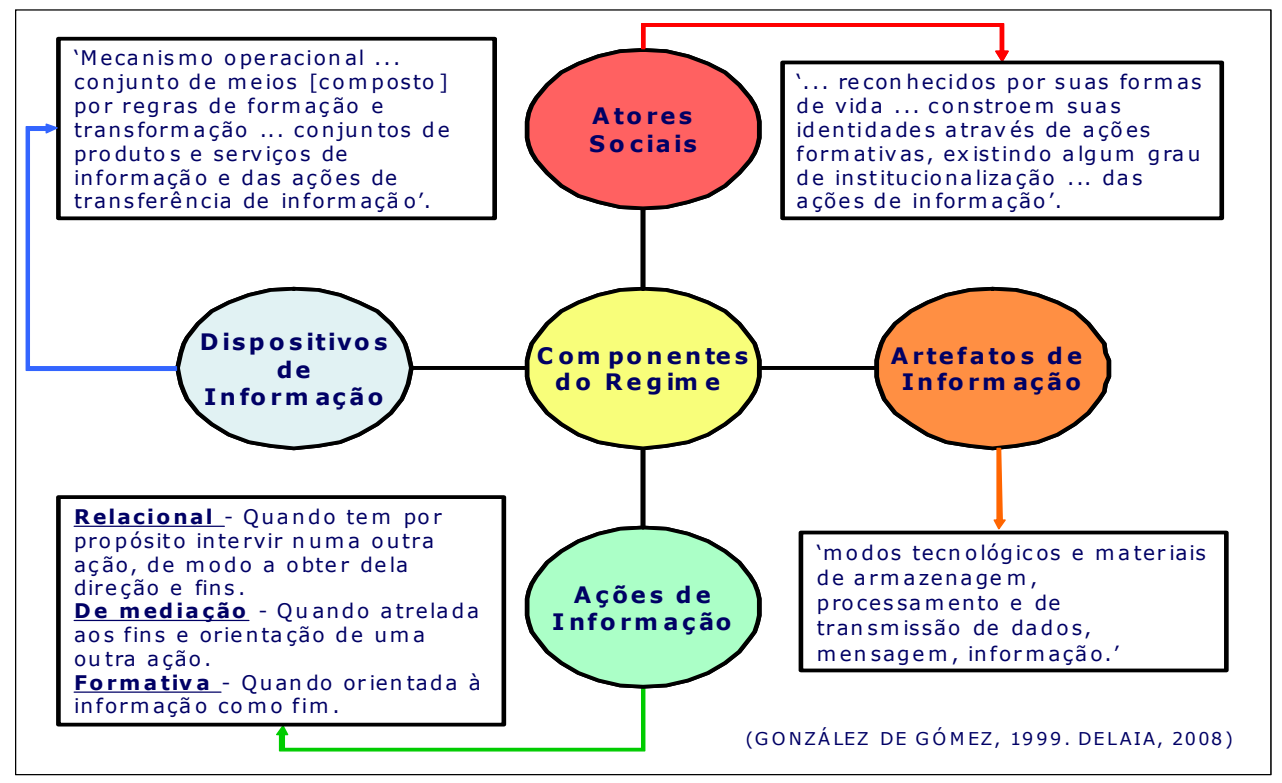

Figura 2 - Descrição gráfica dos elementos de um regime de informação Fonte: DELAIA (2008).

Nesse contexto, a autora descreve os elementos do regime de informação, conforme González de Gómez, a saber:

Dispositivos de informação, considerados um mecanismo operacional, ou um conjunto de meios composto de regras de formação e de transformação desde o seu início, ou ainda, como a autora exemplifica, "um conjunto de produtos e serviços de informação e das ações de transferência de informação" (GONZÁLEZ DE GÓMEZ, 1999, p. 63);

Atores sociais, "reconhecidos por suas formas de vidas e [que] constroem suas identidades através de ações formativas existindo algum grau de institucionalização e estruturação das ações de informação". (GONZÁLEZ DE GÓMEZ, 2003b, p. 35). Os atores estão intrinsecamente relacionados às ações de informação, que propõem e desenvolvem no âmbito de um regime de informação.

Artefatos de informação, que constituem os modos tecnológicos e materiais de armazenagem, processamento e de transmissão de dados, mensagem, informação. (GONZÁLEZ DE GÓMEZ, 2002; 2003b).

Em outra representação gráfica, Delaia (2008) destaca as relações entre os elementos do regime de informação, como na Figura 3: 


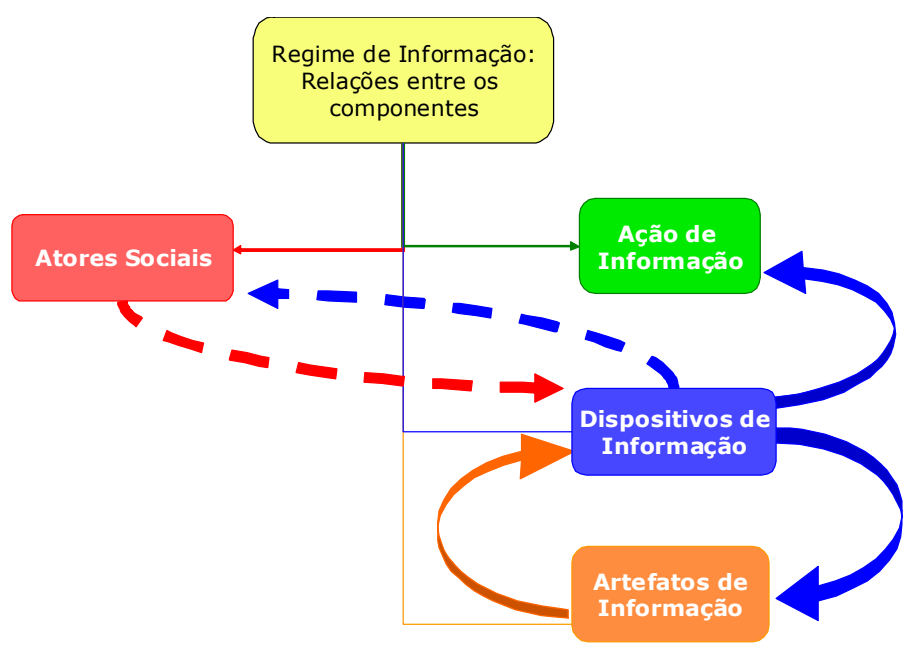

Figura 3 - Relações entre elementos de um regime de informação Fonte: DELAIA (2008).

Nesse quadro de referência, acompanhamos a interpretação de Unger e Freire (2008) quando destacam que é no meio ambiente de trocas materiais (econômicas, tecnológicas, culturais) que ocorrem as relações entre os seres humanos com necessidades informacionais e as fontes de informação e conhecimento relevantes. Os autores acrescentam que regimes são compostos fisicamente por:

a) estoques de informação (produzidos e disseminados no escopo dos sistemas de informação);

b) diretrizes políticas e práticas de gestão que direcionam e organizam os

c) conteúdos informacionais abrigados nos sistemas de informação;

d) seres humanos e suas necessidades informacionais;

e) ambiente social em que os estoques de informação e os seres humanos que os

f) utilizam se inserem;

g) os mecanismos de distribuição do acesso à informação;

h) os meios físicos que permitem o ir e vir da informação (unidades de informação, rede Internet). (Negrito nosso)

Diante desse contexto, concordamos com Unger e Freire (2008, p. 35) em que os regimes de informação "são a substância que dão o caráter principal a um sistema social que passou por diferentes e longas fases até chegar ao estágio atual". Nesse sentido, 
[...] Nos regimes de informação encontramos a totalidade da ambiência entre o conjunto dos itens que dividem este espaço: os seres humanos e as políticas de informação, bem como os estoques de informação formados pelos sistemas de informação. Aos sistemas de recuperação da informação cabe a responsabilidade social de disponibilizar os estoques de informação e também propiciar a acessibilidade às informações armazenadas. (UNGER; FREIRE, 2008, p. 35).

Assim, como interpreta González de Gómez (2002, p. 35), a 'sociedade da informação' pode ser entendida como aquela em que "o regime de informação caracteriza e condiciona todos os outros regimes sociais, econômicos, culturais, das comunidades e do Estado". Nesse contexto,

[...] o ser social que 'migrou' da Sociedade industrial para a Sociedade da informação deve ter condições de responder aos novos imperativos relativos a esta nova estrutura de relações e de produção. E este ser social necessita de suporte informacional para que possa realizar suas aspirações e aquelas que a própria sociedade demanda. (UNGER; FREIRE, 2008, p. 86).

Para a American Library Association (ALA), devemos contribuir para criar uma 'cultura informacional', vista como um conjunto de aptidões e habilidades desenvolvidas para a resolução de problemas de informação localizar, avaliar e usar a informação com eficácia e efetividade. É nesse sentido que o Projeto LTi se propõe constituir um espaço social onde a forma de vida acadêmica possa ser compartilhada, mediante ações de informação em nível de pesquisa - ensino e extensão universitária.

\subsection{Domínios e estratos das ações de informação}

Como visto, o construto 'regime de informação' proposto por González de Gómez (1999; 2002; 2003; 2004) designa o modo de produção informacional numa formação social, no qual ficaria estabelecido quem são os sujeitos, as organizações, as regras e as autoridades normativas no campo da informação. Trata-se do conjunto de determinações onde estão definidos os elementos que compõem o fluxo estrutural dos processos de produção e transferência de informações em um dado espaço social. Nesta perspectiva, a Ciência da Informação

[é] aquela que estuda fenômenos, processos, construções, sistemas, redes e artefatos de informação, enquanto 'informação' for definida por ações de informação, as quais remetem aos atores que as agenciam aos contextos e situações em que acontecem e aos regimes de informação em que se inscrevem. (GONZÁLEZ DE GÓMEZ, 2003a, p. 61, grifos nossos). 
A autora analisa a informação constituída pelas açoes de informação na perspectiva de que estas constituem um conjunto de estratos heterogêneos e articulados, a saber:

a) de informação (semântico-pragmática), estrato polimórfico que se define nos inúmeros setores da produção social sob a forma de ações narrativas;

b) de meta-informação, estrato regulatório definido nos espaços institucionais do Estado, do campo científico, da educação formal, da legislação e dos contratos;

c) de infra-estruturas de informação, estrato mimeomórfico dos objetos de informação, "definido na indústria e nos mercados das tecnologias, das máquinas e dos produtos" mediante "ações tecnoeconômicas, normas técnicas modelos" (GONZÁLEZ DE GÓMEZ, 2003b, p. 34).

Nesse ponto de sua argumentação, González de Gómez (2003b, p. 36) se propõe "melhorar essa conceitualização da informação pela reconstrução do que sejam 'ações de informação', relacionando 'ação social' e 'forma de vida', [tal como propostas por Collins]", entendendo "que uma 'forma de vida' pode estar constituída pelas interações duradouras de um grupo que partilha de atividades, situações e experiências comuns". Sua proposta de trabalho, baseada em Collins e Kush (1999), considera que as 'ações formativas' "são aquelas constitutivas de uma 'forma de vida', a qual singularizam e diferenciam em relação a outros modos de ação e formas de vida" (GONZÁLEZ DE GÓMEZ, 2003b, p. 36). Assim,

Uma ação formativa, por exemplo, na academia, é apresentar uma comunicação num congresso. O que 'fixa' um significado, um discurso, ou pode pré-configurar um 'artefato de informação' em alguma de suas dimensões, não seria logo e em primeiro lugar a base material da inscrição, e sim as condições institucionais e as relações socioculturais entre os sujeitos - incluídas as relações de poder que articulam os artefatos e as infraestruturas de informação em regimes de informação. (GONZÁLEZ DE GÓMEZ, 2003b, p. 36).

A autora concorda com Collins e Kush (1999, p. 19) em que estratos ou dimensões das ações de informação admitem outra leitura, conforme se trate de ações polimórficas ou ações mimeomórficas, esclarecendo que

Ações polimórficas são aquelas que só podem ser compreendidas por quem participa de uma cultura ou forma de vida. Nesse caso, a mesma ação, na mesma situação, pode ser executada conforme um número indefinido de comportamentos e, ao mesmo tempo, uma mesma instância de comportamento pode dar lugar a muitas e diferentes ações. Dado que são ações determinadas por regras, o modo "correto" de 87ráxis87-las só é possível para quem participa 
da forma de vida que é o contexto da ação. O prefixo poli conota "pluralidade" (mayness), referindo-se aos múltiplos comportamentos que podem corresponder a uma mesma ação, assim como aos múltiplos sujeitos implicados (como referência ao social, à polis). (GONZÁLEZ DE GÓMEZ, 2003b, p. 34).

Por sua vez,

Ações mimeomórficas seriam aquelas que poderiam ser reproduzidas tanto por um observador externo - alguém que não compreende sua intencionalidade nem seu contexto de geração -, quanto por quem compreende a ação (COLLINS; KUSH, 1999, p.21). São tipos de ações pré-modeladas que podem apreender-se através de exemplos, por treinamento. Tal como discar num telefone ou 'clicar' um ícone do Windows. (GONZÁLEZ DE GÓMEZ, 2003b, p. 34).

Assim, e partir da abordagem de Collins e Kush (1999), González de Gómez (2003, p.36) reconhece três modalidades de manifestação de uma ação de informação, conforme o contexto de sua constituição em um dado regime de informação:

a) de mediação (quando a ação de informação fica atrelada aos fins e orientação de uma outra ação);

b) formativa (aquela que é orientada à informação não como meio mas como sua finalização);

c) relacional (quando uma ação de informação tem como finalidade intervir numa outra ação de informação, de modo que - ainda quando de autonomia relativa - dela obtém a direção e fins)

A seguir, apresentamos o quadro de González de Gómez com a teleologia das ações de informação:

Quadro 1 - Teleologia das ações de informação

\begin{tabular}{l|l|l|l}
\hline \multicolumn{1}{c|}{$\begin{array}{c}\text { Ações de } \\
\text { Informação }\end{array}$} & \multicolumn{1}{c|}{ Atores } & \multicolumn{1}{c}{ Atividades } & \multicolumn{1}{c}{ [Finalidade] } \\
\hline \hline Mediação & $\begin{array}{l}\text { Sujeitos Sociais } \\
\left.\text { Funcionais (práxis }{ }^{5}\right)\end{array}$ & $\begin{array}{l}\text { Atividades Sociais } \\
\text { Múltiplas }\end{array}$ & $\begin{array}{l}\text { Transformar o mundo } \\
\text { social ou natural }\end{array}$ \\
\hline $\begin{array}{l}\text { Formativa ou } \\
\text { Finalista }\end{array}$ & $\begin{array}{l}\text { Sujeitos Sociais } \\
\text { Experimentadores } \\
\left(\text { poiesis }^{6}\right)\end{array}$ & $\begin{array}{l}\text { Atividades Heurísticas e } \\
\text { de Inovação }\end{array}$ & $\begin{array}{l}\text { Transformar o } \\
\text { conhecimento para } \\
\text { transformar o mundo }\end{array}$ \\
\hline $\begin{array}{l}\text { Relacional } \\
\text { Inter-Meta-Pós- } \\
\text { mediática }\end{array}$ & $\begin{array}{l}\text { Sujeitos Sociais } \\
\text { Articuladores e } \\
\left.\text { Reflexivos (legein }{ }^{7}\right)\end{array}$ & $\begin{array}{l}\text { Atividades Sociais de } \\
\text { Monitoramento, } \\
\text { Controle e Coordenação }\end{array}$ & $\begin{array}{l}\text { Transformar a informação } \\
\text { e a comunicação que } \\
\text { orientam o agir coletivo }\end{array}$ \\
\hline
\end{tabular}

\footnotetext{
5 Práxis - No campo científico, entende-se como uma prática profissional em que os atores sociais atuam a partir de uma teoria que é a base para sua ação no mundo.

6 Poiesis - "[...] quando a ação de informação no contexto formativo é gerada por sujeitos sociais heurísticos ou 'experimentadores', transformando os modos culturais de agir e de fazer, nas artes, na política, na ciência, na indústria e no trabalho, iniciando um novo domínio informacional." (GONZÁLEZ DE GÓMEZ, 2003b, p. 36, grifos nossos).
} 
Fonte: GONZÁLEZ DE GÓMEZ (2003b, p. 37).

É nesse contexto que as ações de pesquisa e as ações de informação integram um mesmo domínio de orientações estratégicas e, como consequência, "a política e a gestão da informação formarão parte do mesmo plano decisional e prospectivo ao qual pertence a política e a gestão da ciência e tecnologia" (GONZÁLEZ DE GÓMEZ, 2003a, p. 61).

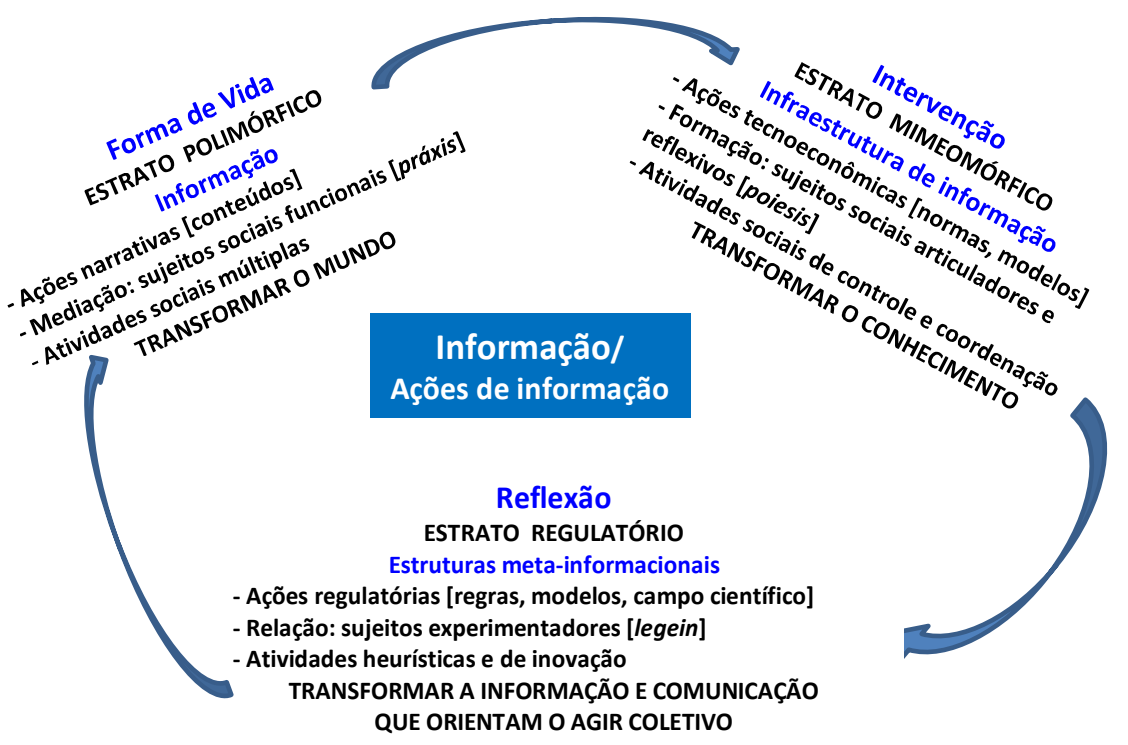

Figura 4 - Ações de informação: domínios, estratos, sujeitos e finalidades Fonte: Elaboração da autora.

A seguir, apresentamos um diagrama descritivo das modalidades de ações de informação em desenvolvimento pela rede de projetos, em nível de pesquisa - ensino - extensão, no Projeto LTi:

\footnotetext{
${ }^{7}$ Legein - "[...] quando uma ação de informação intervém em [uma] outra [...], duplicando o espaço de realização [desta, de modo a ampliar as] formas de descrição, da facilitação, do controle ou do monitoramento, $[\ldots]$ realizadas por sujeitos articuladores ou relacionantes." (GONZÁLEZ DE GÓMEZ, 2003b, p. 36, grifos nossos).
} 


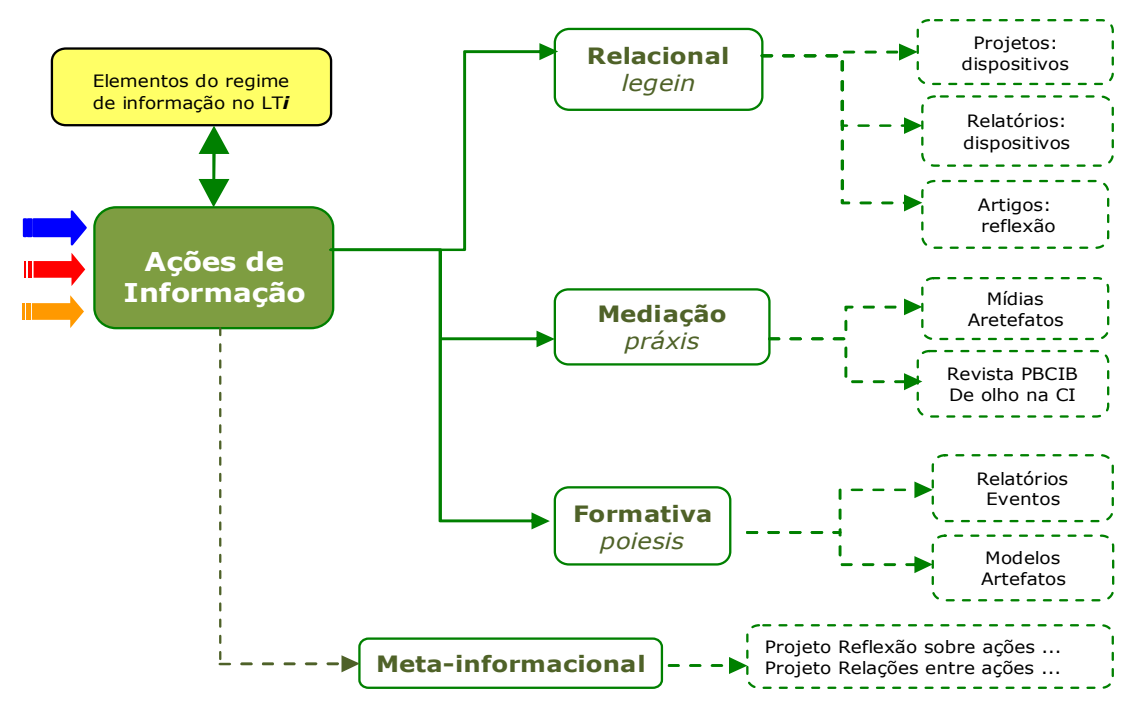

Figura 5 - Modalidades de ações de informação no LTi

Fonte: Elaboração da autora.

Com este modelo de abordagem, argumentamos que o campo da Ciência da Informação pode proporcionar recursos teóricos e tecnológicos que promovam as competências necessárias para a socialização da informação. Neste caso, é possível propor uma ação que possibilite a união desses contextos em um espaço social no qual os profissionais da informação possam desenvolver ações com vistas à gestão de recursos para promover a inclusão na Sociedade da Informação e do Conhecimento.

Para González de Gómez (2003b, p. 38), essa abordagem singulariza a Ciência da Informação no campo científico e a coloca "numa posição preferencial para fortalecer o olhar comunicacional e gnosiológico em processos e domínios que até agora têm sido explicitados à luz de fatores econômicos ou tecnológicos".

Nesse contexto, as ações da rede de projetos para disseminação, produção e comunicação da informação contribuem, conforme modelo teórico-operativo descrito, para o desenvolvimento de habilidades de busca, recuperação, propagação e apropriação de informações relevantes por usuários na sociedade - quadro de referência em que se fundamenta a proposta do LTi.

\section{Reflexão sobre as ações de informação no lti}

Em nível operacional, o LTi está sendo implementado através de uma rede de projetos, em correspondência às atividades acadêmicas da UFPB e em conformidade com o 'método de projeto', considerado por Lück (2001, p. 13) como uma "ferramenta básica do gestor, que [...] fundamenta, direciona e organiza a ação de sua responsabilidade [e] possibilita o seu monitoramento e avaliação". Nesta perspectiva, 'projeto' é definido como 
[...] um conjunto organizado e encadeado de ações de abrangência e escopo definidos, que focaliza aspectos específicos a serem abordados num período determinado de tempo, por pessoas associadas e articuladoras das condições promotoras de resultados. (LÜCK, 2001, p. 23).

A rede de projetos do LTi é constituída por projetos de ações de informação no âmbito de cada uma das linhas de atuação universitária: ensino, pesquisa, extensão. Professores do Departamento de Ciência da Informação (DCI) e do Programa de Pós-Graduação em Ciência da Informação (PPGCI) da UFPB participam da rede, através de projetos que estão em desenvolvimento, em elaboração, ou em fase de discussão dos resultados. Cada projeto é autônomo e diferenciado em sua proposta e equipe, embora vinculado à proposta do LTi como informação/ação de informação no campo da Ciência da Informação.

Dessa forma, as ações desenvolvem entre os participantes uma sinergia para 0 trabalho a ser empreendido, além de gerar comprometimento com a efetiva construção de condições para sua realização, com o propósito de promover benefícios às pessoas e organizações. Representa, também, a oportunidade para as pesquisadoras proponentes tecerem, no tear da Ciência da Informação, um padrão que (re)una informação e computação em nível da integração entre pesquisa ensino - extensão, na práxis acadêmica.

Nos três níveis de atividades do LTi, a rede de projetos visa alcançar os seguintes objetivos:

a) na pesquisa - propor, experimentar e avaliar um modelo de ação de informação para promover o compartilhamento de recursos de informação e a comunicação científica sobre a proposta e resultados (eventos, publicações);

b) no ensino - contribuir, de forma propositiva, para qualidade do trabalho acadêmico nas disciplinas curriculares da graduação e pós-graduação;

c) na extensão - promover oportunidades para transferência de tecnologias intelectuais, mediante oficinas presenciais e tutoriais on line para competências em informação, bem como prestação de serviços de referência na web.

Os objetivos propostos nos auxiliaram na tarefa de mapear as modalidades das ações de informação em desenvolvimento no LTi, conforme descritas por González de Gómez (2003a; 2003b) e analisadas por Freire (2013).

Nesse sentido, observamos que as atividades podem ser vistas como "ações de informação, as quais remetem aos atores que as agenciam, aos contextos e situações em que acontecem e aos regimes de informação em que se inscrevem", como esclarece González de Gómez 
(2003a, p. 61) sobre o campo de interesse da Ciência da Informação. Ademais, o uso de termos como "compartilhamento de recursos de informação", "contribuir de forma propositiva" e "promover oportunidades para transferência de tecnologias intelectuais" nos dá pistas sobre o pressuposto dessas atividades, qual seja a responsabilidade social da Ciência da Informação, na sociedade contemporânea.

Com relação à caracterização dos estratos dessas atividades enquanto ações de informação, devemos lembrar que esses estratos são heterogêneos e articulados, ocorrendo "de modo paralelo e simultâneo ao longo de todo o desenvolvimento de uma atividade ou processo" (GONZÁLEZ DE GÓMEZ, 2003b, p. 33). Essas ações de informação podem ser reunidas e interpretadas em nível dos domínios e finalidades das ações de informação, bem como dos sujeitos das ações, a saber:

a) no domínio da legein, no extrato regulatório das ações inter-meta-pós-midiáticas realizadas por sujeitos articuladores ou relacionantes, em nível das atividades de pesquisa, para criação de modelos, análise e avaliação dos projetos em desenvolvimento no âmbito do LTi;

b) no domínio da poiesis, das ações formativas ou finalistas realizadas por sujeitos heurísticos ou experimentadores, em nível das atividades de ensino, para desenvolvimento de competências em informação nos alunos de pós-graduação em Ciência da Informação e de graduação em Biblioteconomia e Arquivologia da UFPB;

c) no domínio da práxis, das ações de mediação ou informativas realizadas por sujeitos sociais funcionais, em nível das atividades de extensão, na forma de prestação de serviços de informação mediados pela interface virtual do Portal LTi.

No quadro 2, a seguir, descrevemos os domínios e aplicações das ações de informação em curso no LTi: 
Quadro 2 - Domínios, finalidades e aplicações das ações de informação no $\mathrm{LT} i$

\begin{tabular}{|c|c|c|c|}
\hline Domínios & Ações de informação & Finalidades & Ações de informação no LT $i$ \\
\hline$L E G E I N$ & $\begin{array}{l}\text { Relacionais Inter- } \\
\text { Meta-Pós- } \\
\text { mediáticas. } \\
\text { Atividades } \\
\text { sociais múltiplas. }\end{array}$ & $\begin{array}{l}\text { Transformar a informação } \\
\text { e a comunicação que } \\
\text { orientam o agir coletivo. } \\
\text { Extrato regulatório. }\end{array}$ & $\begin{array}{l}\text { Ações regulatórias } \\
\text { PESQUISA/Projeto LTi } \\
\text { - Rede de projetos }\end{array}$ \\
\hline POIESIS & $\begin{array}{l}\text { Ações formativas } \\
\text { ou finalistas. } \\
\text { Atividades } \\
\text { heurísticas e de } \\
\text { inovação. }\end{array}$ & $\begin{array}{l}\text { Transformar o } \\
\text { conhecimento para } \\
\text { transformar o mundo. } \\
\text { Extrato mimeográfico. }\end{array}$ & $\begin{array}{l}\text { Ações formativas } \\
\text { ENSINO/Disciplinas UFPB } \\
\text { - Tutoriais e outros }\end{array}$ \\
\hline PRAXIS & $\begin{array}{l}\text { Ações de mediação. } \\
\text { Atividades sociais } \\
\text { de Controle, } \\
\text { Monitoramento e } \\
\text { Coordenacão. }\end{array}$ & $\begin{array}{l}\text { Transformar o mundo } \\
\text { social ou natural. } \\
\text { Extrato polimórfico }\end{array}$ & $\begin{array}{l}\text { Ações mediadoras } \\
\text { PESQUISA/Modelos } \\
\text { ENSINO/Conteúdos } \\
\text { EXTENSÃO/Resultados }\end{array}$ \\
\hline
\end{tabular}

Fonte: Elaborado pela autora.

Assim, na perspectiva do estrato de informação (semânticopragmático), trata-se de projeto direcionado ao setor científico e tecnológico da produção social, particularmente à comunidade acadêmica e aos profissionais da informação. Nesse sentido, o aspecto polimórfico da ação expressa as "heterogeneidades e singularidades dos [mundos de vida] dos sujeitos", como esclarece González de Gómez (2003, p. 34) em relação às características desse estrato, procurando atender docentes, discentes, pesquisadores e profissionais técnicos. Na perspectiva do estrato meta-informacional, as atividades da rede de projetos do LTi se inserem nos espaços institucionais do Estado (mediante as políticas governamentais de fomento à Ciência e Tecnologia), do campo científico (sendo um projeto de pesquisa), da educação formal (vinculado a instituição de ensino superior), da legislação (práticas são orientadas por regulamentos) e dos contratos (termos de concessão de recursos). É neste domínio regulatório que

[...] se estipula o domínio relacional [...] dentro do qual algo apresenta ou representa um valor de informação [...] o contexto a partir do qual aquilo que adquire caráter de informação pode desenvolver valores cognitivos, constituir evidências probatórias, servir de apoio a decisão ou ser insumo de ações instrumentais. (GONZÁLEZ DE GÓMEZ, 2003b, p. 35).

Esse estrato é representado pelas atividades de pesquisa propriamente ditas, que concorreram a apoio institucional através de editais públicos de instituições de fomento à Ciência e Tecnologia e estão apoiadas em contratos de alocação de recursos, ou de programas específicos de apoio à atividade acadêmica na UFPB, concorrendo em programas de bolsas para graduação e pós-graduação. Este é o domínio 
relacional onde o Projeto LTi assume sua feição de informação em si, atendendo aos objetivos propostos nos três níveis da atividade universitária, quais sejam ensino - pesquisa - extensão, criando, nesse processo, evidências comprobatórias sobre a validade dos pressupostos teóricos da pesquisa e dos seus resultados na sociedade.

Por fim, o estrato mimeográfico de infra-estruturas de informação, "definido na indústria e nos mercados das tecnologias, das máquinas e dos produtos [... mediante ações tecnoeconômicas, normas técnicas, modelos" (GONZÁLEZ DE GÓMEZ, 2003b, p. 34), diz respeito aos objetos de informação criados pelas atividades do LTi, dos quais o sítio virtual é o principal representante. ${ }^{8}$ Este estrato

Remete àquilo que disponibiliza e deixa disponível, como sua mediação sócio-cultural, um valor de informação, e que poderíamos caracterizar como ação tecnoeconômica - de antecipação estruturante na configuração da ação/informação. Para referirmonos a tudo aquilo que, como matéria informada, mediação maquínica ou como passado instituído domundo social, condiciona e limita uma ação de informação, poderíamos falar de 'dispositivos de informação' ou de 'artefatos de informação' - ou, preferimos hoje - 'objetos relacionais', quando enfatizamos a instância da inscrição e objetivação de um testemunho ou evidência informacional como objeto cultural. (GONZÁLEZ DE GÓMEZ, 2003b, p. 35).

Dessa forma, o Projeto LTi se caracteriza como uma informação/ação de informação de interesse para o campo da informação, compreendendo uma intervenção direcionada para uma 'forma de vida' constituída "pelas interações duradouras de um grupo que partilha de atividades, situações e experiências comuns", conforme González de Gómez (2003b, p. 36) no campo da Ciência da Informação.

Ademais, trata-se de uma 'ação formativa', no sentido de Collins e Kush (1999), descrita por González de Gómez (2003b) como aquela que é constitutiva da forma de vida de um grupo, o qual singulariza e diferencia em relação a outros modos de ação e formas de vida. Nesse contexto, a autora corrobora que "os atores sociais [sujeitos] estão de acordo em seus conceitos porque [...] partilham uma realidade de ações possíveis e estão de acordo em suas ações porque [...] partilham uma rede comum de conceitos" (GONZÁLEZ DE GÓMEZ, 2003b, p. 36). Essa rede comum de conceitos propicia, efetivamente, uma 'cultura informacional' compartilhada pelos atores sociais envolvidos em todos os níveis de atividade do LTi, os quais constituem a forma de vida dessa comunidade de docentes e discentes vinculados aos cursos em Ciência da Informação, Biblioteconomia e Arquivologia da UFPB.

Destarte, as ações de informação em desenvolvimento no LTi também podem ser descritas em termos dos elementos do regime de informação, destacando-se, ademais, os atores, dispositivos e artefatos ou

\footnotetext{
${ }^{8}$ Disponível em <http://www.Iti.pro.br>. Acesso em: 12 dez. 2015.
} 
objetos relacionais. Esses elementos serão objeto de uma próxima reflexão.

\section{REFERÊNCIAS}

AMERICAN LIBRARY ASSOCIATION. Presidential Committee on Information Literacy. Chicago: ALA, 1989. Final report. Disponível em: <http://www.ala.org/acrl/nili/ilit1st.html. Acesso em 2001>. Acesso em: 26 ago. 2006.

COLLINS, H. M.; KUSH, M. The shape of actions: what humans and machines can do. Cambridge, Mass: MIT Press, 1999. p. 11-21.

DELAIA, C. R. Subsídios para uma política de gestão da informação na EMBRAPA Solos. 2008. 243f. Dissertação (Mestrado em Ciência da Informação) - IBICT, UFF, Niterói, 2008.

FREIRE, I. M. Categorização das ações de informação no laboratório de tecnologias intelectuais (LTi). Tendências da Pesquisa Brasileira em Ciência da Informação, v. 5, n. 1, 2013.

FREIRE, I. M. A rede de projetos do núcleo temático da seca da UFRN como possibilidade de socialização da informação. Informação \& Sociedade: Estudos, João Pessoa, v. 14, n. 2, p. 201-216, 2004.

FREIRE, I. M. A responsabilidade social da Ciência da Informação e/ou $O$ olhar da consciência possível sobre o campo científico. 2001. 240f. Tese (Doutorado em Ciência da Informação) - IBICT, UFRJ, Rio de Janeiro, 2001.

FROHMANN, B. Taking information policy beyond information science: applying actor network theory. In: ANNUAL CONFERENCE OF THE CANADIAN ASSOCIATION FOR INFORMATION SCIENCE / ASSOCIATION CANADIENNE DES SCIENCES DE L'INFORMATION, 23., 1995. Edmonton. Electronic proceddings... Otawa: CAIS, 1995. 14p. Disponível em: <http://www.cais-acsi.ca/1995proceedings.htm>. Acesso em: 10 maio 2005.

GONZÁLEZ DE GÓMEZ, M. N. Da política de informação ao papel da informação na política contemporânea. Revista Internacional de Estudos Políticos, v. 1, n. 1, p. 57-93, 1999.

GONZÁLEZ DE GÓMEZ, M. N. Novos cenários políticos para a informação. Ciência da Informação, v. 31, n. 1, p. 27-40, 2002.

GONZÁLEZ DE GÓMEZ, M. N. As relações entre ciência, estado e sociedade: um domínio de visibilidade para as questões da informação. Ciência da Informação, v. 32, n. 1, p. 60-76, $2003 a$.

GONZÁLEZ DE GÓMEZ, M. N. Escopo e abrangência da Ciência da Informação e a pós-graduação na área: anotações para uma reflexão. Transinformação, v. 15, n. 1, p. 31-43, 2003b. 
GONZÁLEZ DE GÓMEZ, M. N. Novas fronteiras tecnológicas das ações de informação: questões e abordagens. Ciência da Informação, v. 33, n. 1, p. 55-67, 2004.

LÈVY, P. As tecnologias da inteligência: o futuro do pensamento na era da informática. Rio de Janeiro: 34, 1994.

LÈVY, P. Cibercultura. São Paulo: 34, 1999.

LÈVY, P. A inteligência coletiva: por uma antropologia do ciberespaço. 3. ed. São Paulo: Loyola, 2000.

LÜCK, H. Metodologia de projetos: uma ferramenta de planejamento e gestão. 2. ed. Petrópolis: Vozes, 2001.

UNGER, R. J. G.; FREIRE, I. M. Regimes de informação na sociedade da informação: uma contribuição para a gestão de informação. Revista Digital de Biblioteconomia e Ciência da Informação, v. 4, n. 1, p. 87-114, jan./jun. 2008.

WERSIG, G. Information science: the study of postmodern knowledge usage. Information Processing \& Management, v. 29, n. 2, p. 227-248, 1993.

WERSIG, G., NEVELING, U. The phenomena of interest to information science. The Information Scientist, v. 9, n. 4, p. 187-219, 1975. 